\title{
Towards an improved decision-making process to better cope with uncertainties following a nuclear accident
}

\author{
V. Durand ${ }^{1, *}$, M. Maître ${ }^{2}$, P. Crouaï ${ }^{2}$, T. Schneider ${ }^{2}$, R. Sala ${ }^{3}$, P. Marques-Nunes ${ }^{4}$, I. Paiva ${ }^{5}$, \\ O. Monteiro Gil ${ }^{5}$, M. Reis ${ }^{5}$, C. Hilliard ${ }^{6}$, V. Tafili ${ }^{7}$, C. Twenhöfel ${ }^{8}$, E. Van Asselt ${ }^{9}$, C. Trueba ${ }^{3}$, \\ M. Montero ${ }^{3}$ and T. Duranova ${ }^{10}$ \\ ${ }^{1}$ IRSN-Radiation Protection and Nuclear Safety Institute, Fontenay-aux-Roses, France. \\ ${ }^{2}$ CEPN-Nuclear Protection Evaluation Centre, Fontenay-aux-Roses, France. \\ ${ }^{3}$ CIEMAT - Centro de Investigaciones Energéticas, Medioambientales y Tecnológicas, Madrid, Spain. \\ 4 APA-Portuguese Environment Agency, Amadora, Portugal. \\ 5 IST-C2TN-Instituto Superior Técnico, Centro de Ciências e Tecnologias Nucleares, Lisbon, Portugal. \\ ${ }^{6}$ EPA - Environmental Protection Agency, Dublin, Ireland. \\ ${ }^{7}$ EEAE-Greek Atomic Energy Commission, Athens, Greece. \\ 8 RIVM-Rijksinstituut voor Volksgezondheid en Milieu, Bilthoven, The Netherlands. \\ ${ }^{9}$ WFSR - Wageningen Food Safety Research, Wageningen, The Netherlands. \\ ${ }^{10}$ VUJE-VUJE a.s., Trnava, Slovak Republic.
}

\begin{abstract}
An emergency situation is subject to multiple sources of uncertainties which should be identified in advance in order to improve the emergency and recovery management, and so optimally foster the living conditions of the population and the quality of their environment. In this context, the Work Package 4 of the European Research Project CONFIDENCE aimed at identifying and reducing uncertainties which could emerge in decision-making processes, in order to improve the preparedness and response after a nuclear accident. To that end, stakeholder panels have been set up in several European countries to collect their views and concerns regarding the decisions to be taken in the event of a nuclear crisis (e.g. evacuation, food restrictions, etc.). More particularly, the implementation of these panels allowed the researchers to (i) identify the main uncertainties that may hamper decision-making processes and to (ii) evaluate the influence of prior decisions made during the emergency phase over the medium to long-term evolution of the situation. Based on these discussions, the various types of uncertainties raised by the national panels have been analysed in order to suggest recommendations to better consider them and to improve the decision-making processes. This paper aims to detail the recommendations resulting from the panels discussions.
\end{abstract}

Keywords: nuclear accident / emergency and transition phases / uncertainties / decision-making process / recommendations / emergency preparedness and response / post-accident recovery

\section{Introduction}

The Work Package 4 (WP4) of the European Research Project CONFIDENCE (COping with uNcertainties For Improved modelling and DEcision making in Nuclear emergenCiEs) aimed at identifying and reducing major uncertainties which could emerge in decision making processes, in order to improve the preparedness and response after a nuclear accident. To that end, stakeholder panels have been set up in different European countries to collect their views and concerns regarding decisions to be taken in the event

\footnotetext{
*Corresponding author: vanessa.durand@irsn.fr
}

of a nuclear crisis (e.g. review or lifting of the initial protective actions, food and water control, urban decontamination, etc.). The main findings of the national panels are presented in Montero et al. (2020). Among these elements, the panels emphasized that an emergency situation brings multiple types of uncertainties. These should be better considered in order to optimally improve the living conditions of the affected population and the overall quality of their environment. The various uncertainties highlighted by the national panels can be broadly divided in two categories: those associated with the production of information (i.e. uncertainties external to the decision-making process related to modelling, field measurements, calculation errors, etc.) and those linked with the use of information (i.e. uncertainties internal to the decision-making 
process related to the decision itself, its implementation and governance and its possible social and economic impacts). To refine the categorization of internal uncertainties raised by the national panels, five main categories have been defined (Montero et al., 2020): i) Governance aspects; ii) Environmental issues; iii) Human health and safety issues; iv) Social aspects; v) Economic aspects. An additional category dedicated to "Transversal issues" has also been considered, referring more particularly to "external uncertainties", and notably issues related to the provision of information which can better guide decision-makers. On this basis, recommendations have been prepared to better mitigate these uncertainties, thus improving the decision-making processes in the transition phase and even the preparedness for the emergency response.

This paper describes (i) the methodology developed to elaborate the recommendations, and (ii) the 14 elaborated recommendations, by explaining the overall context that suggested them, as well as what is encouraged in practical terms.

\section{Methodology}

The methodology developed to elaborate these recommendations is based on the discussions within each national panel, as well as on exchanges among WP4 partners. It also relies on exchanges among the CONFIDENCE project partners and endusers at the occasion of the CONFIDENCE final dissemination workshop that took place in Bratislava, from the 2 nd to the 5 th of December 2019 (Duranova et al., 2020). As a first step, all partners of the WP4 were asked to select for each of the six categories of uncertainties defined in Montero et al. (2020), the most important ones raised from their panels' discussions. Based on this selection, each partner had to suggest recommendations that could help to better consider, or even reduce, these main uncertainties in the decision-making processes. They were also invited to suggest broad enough recommendations that can address several uncertainties at once.

In the second step, within the WP4 partners, six working groups (WG) were set up, covering the six pre-defined categories of uncertainties: Environment, Economy, Social, Human Health and Safety, Governance and Transversal (dedicated to communication and support of information issues). The objective was to harmonize and further elaborate the recommendations with the aims to be broad enough to have a European scope, to address the expectations of the national panels, and to favour practical actions for the future.

In the third step, the recommendations drawn up by each WG were presented and discussed with other CONFIDENCE partners and end-users at the occasion of the dissemination workshop (Duranova et al., 2020). Thanks to round table discussions, the participants expressed their views and suggestions to improve this first set of recommendations. These comments were taken into account to finalize the recommendations presented in this paper. The Figure 1 summarizes this 3step-methodology.

\section{Recommendations for improving decision- making process}

A set of 14 recommendations has been elaborated from the above approach for an implementation in the preparedness phase (see Fig. 2). These recommendations are described in the following paragraphs, including the overall context that led to suggest them (some of the questions formulated by the national panels are sometimes quoted), and what is recommended in practical terms.

In order to implement these recommendations, various actors can be involved, as for instance radiological protection professionals (e.g. experts, modellers and nuclear operators), researchers (e.g. economists, psychologists), national and local authorities, socio-economic actors, health professionals, environmental NGOs, international organisations and local population.

\subsection{Governance aspects}

In the aftermath of a nuclear accident, the governance of the decision-making process raises a large number of uncertainties from the emergency to recovery phases. It is important to stress that, in the case of a nuclear crisis, decisions are complex by nature and cannot rely only on decision-makers and experts from the radiological protection field (Ban, 2016). Other actors (such as national and local elected people, socioeconomic actors (farmers, artisans, business people, etc.), health professionals, health/food/environmental agencies, inhabitants, operators or neighbouring countries) may support the decision-making processes. However, their roles and responsibilities are not always clear, especially during the transition phase when the tasks of local and national decisionmakers and potential transfers of responsibility are not well anticipated. The stakeholder panels raised strong uncertainties about how to balance local, national and international interests in the decision-making process. Indeed, in case of an accident, strategies envisaged at the local level may not be implemented by decision-makers at the national level, leading them to question their real power in the decision. The panels also raised other uncertainties related to governance issues, and more particularly, to the decision-making process itself. For instance, the timing of decisions raises important uncertainties: "what is the best timing to take a decision: on the basis of the first model assessments or should we wait for the first map of contamination based on field measurements?". Panels also highlighted that decisions taken during the emergency phase can have consequences on the long-term management of the situation (Baudé et al., 2016). Therefore, facing this observation, one of the challenges of the transition phase is to bring flexibility on the decision-making process and to adapt the early decisions by considering the potential evolution of the situation and decision-makers changes (e.g. change of management organisation between emergency and long-term phases). To better cope with these types of uncertainties some of which are closely related to external uncertainties, some recommendations have been suggested. Initially, it would be helpful to clarify roles and responsibilities of the different actors involved in the decision-making process to better coordinate their actions in a context of uncertainty. Concrete actions could be:

- to work on feedback analyses of former crises management (nuclear or others) to challenge the roles and responsibilities of the different actors and the coordination of the actions according to existing emergency and national 


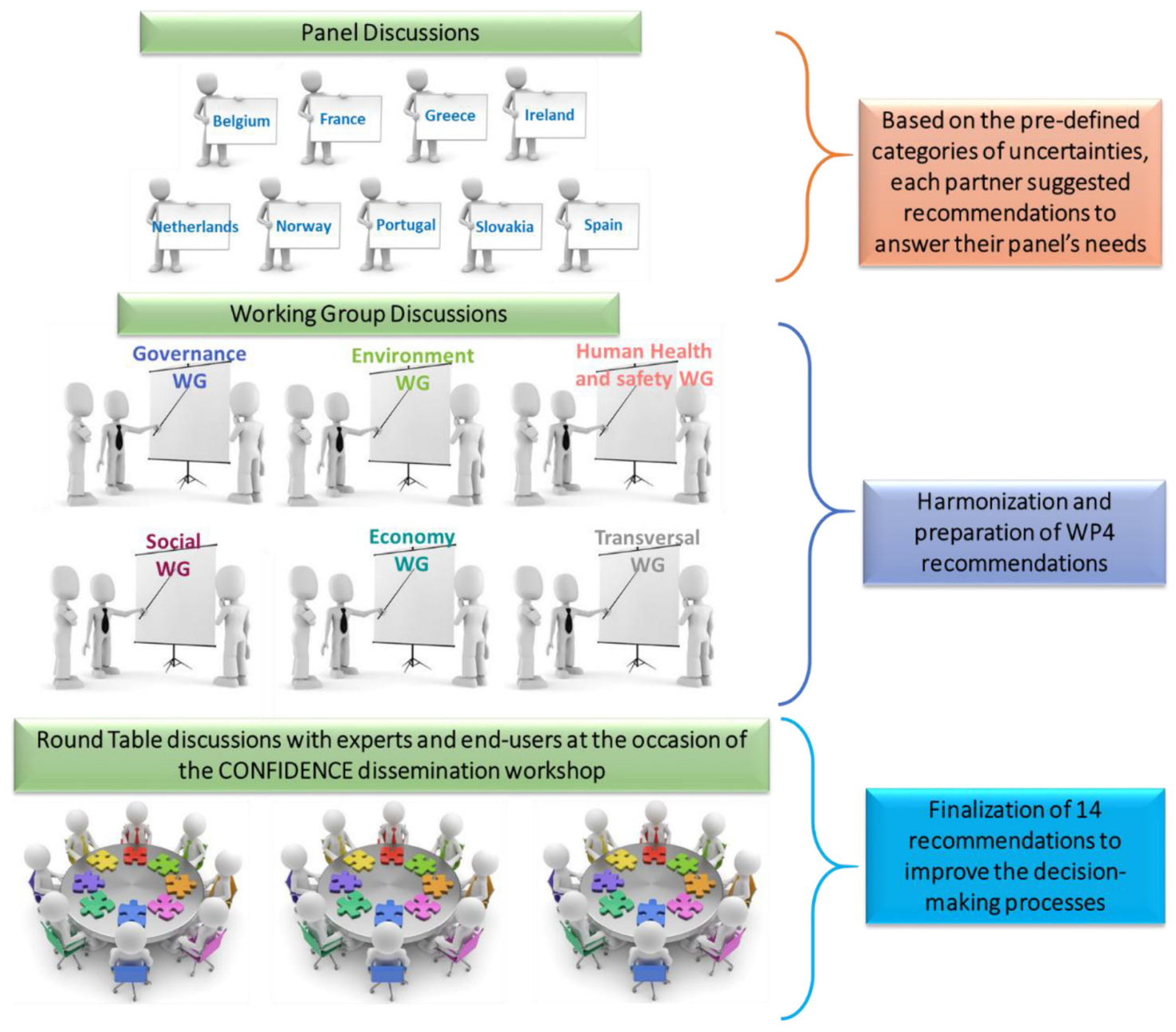

Fig. 1. Methodology developed to elaborate the WP4 CONFIDENCE recommendations.

response plans, focusing particularly on the transition phase;

- based on the outcomes of such analyses, enlarge the sphere of actors to be involved in the decision-making process, with precisions on how and when they should intervene;

- to develop national exercises to better define and strengthen the coordination between decision-makers, notably during the transition phase. There is a particular need to focus on specific decisions that could significantly impact the future of the affected communities (e.g. implementation and lifting of evacuation and food restriction orders);

- set up cross-border exercises with neighbouring countries to converge on population protection strategies, land management strategies and information processes.

It could also be useful to develop a dynamic approach to implement more flexible decision-making processes. This recommendation would imply actions:

- to adapt the organisation of the decision-making processes (at local, regional, national, international levels) for emergency and transition phases and their evolution over time. On this basis, new approaches of cooperation for strengthening the dynamics between the different actors involved could be implemented;

- to develop tools facilitating dynamic approaches in the decision-making processes and helping decision-makers to have a comprehensive vision of the on-going situation and to formulate flexible decisions during the transition phase (e.g. maps projecting the evolution of the radiological contamination over time, "options thinking" tools whose specific purpose is to enable the delay of final decisions to the point where better information is available, etc.);

- to challenge the operational tools developed in the previous steps and the dynamics approaches of decision-making process through exercises, practical case studies, etc.

Associated with these governance aspects, the place of local stakeholders, who face the reality of the affected territory and who are likely to be directly involved in the management of the long-term situation remains a real challenge which raises uncertainties: "Who, how and when to involve local stakeholders in the decision-making process and in the planning of countermeasure strategies?" "How to adapt strategies according to their needs and expectations?". Moreover, in the case of a nuclear accident, the need to implement protective actions in 


\section{GOVERNANCE}

1) Clarify roles and responsibilities of the different actors involved in the decision-making process to better coordinate their actions in a context of uncertainty

2) Set up a stakeholder network to facilitate the involvement of local actors in the preparedness of emergency response and recovery

3) Develop dynamic approach to implement more flexible decision-making processes

ENVIRONMENT
4) Better consider the seasonality of agricultural
productions and living conditions of animal productions
to adapt countermeasures and protective actions to the
actual situation
5) Further develop or maintain a comprehensive and
effective monitoring capability
6) Anticipate the waste consequences linked to the
protective decision and prepare the means for an
appropriate management

SOCIAL

8) Gather information on post-disaster behaviour of population and adapt, if necessary, the emergency response strategies

9) Investigate innovative strategies of communication on uncertainties related to the implementation of protective actions

\section{HUMAN HEALTH AND SAFETY}

7) Set up a framework for implementing health surveillance strategy in post-accident situation

\section{TRANSVERSAL ISSUES}

13) Foster the production and the provision of comprehensive information for the decision-making process

14) Improve the support of information reflecting uncertainties inherent in the situation to better guide decision-makers

Fig. 2. Overall structure of the recommendations.

accordance with the specificities of a territory and the expectations of local stakeholders have been already acknowledged in previous research projects (e.g. Gallego and Montero, 2016; Averin, 2016; Charron et al., 2016; Raskob et al., 2016). This research calls for opening discussions with local stakeholders on the emergency preparedness and response aspects to collect their needs and expectations, which would bring greater credibility and legitimacy to the decision-making process itself. However, the involvement of local stakeholders on the preparedness of emergency and recovery issues is a real challenge. Some countries already have organized discussions on this topic by implementing local-national stakeholder panels in the framework of former European projects (e.g. SAGE, EURANOS, FARMING, NERIS TP, PREPARE, etc.), but it is not so trivial and these panels have not been sustained over time. Therefore, one question remains: "How to develop sustainable dialogue with local stakeholders on preparedness of emergency and recovery issues?" To address this issue, one recommendation is to foster the setting up of a stakeholder network to facilitate the involvement of local actors in the preparedness of emergency response and recovery. Practical actions are to:

- identify the different local actors who have an interest, to discuss (on a voluntary basis) specificities of their territory to be considered for the management of an accident (e.g. local socio-economic actors, local elected people, environmental NGOs, etc.), depending on the political and cultural context of each country;

- set up a stakeholder network which includes different categories of actors (e.g. institutional and non-institutional organisations, international, national and local public authorities, local socio-economic actors, local elected people, environmental NGOs, etc.) and covers the breadth of emergency response and recovery management topics;

- clarify in advance the role and the influence of this network in the preparedness of emergency response and recovery as well as in the decision-making process in case of an accident and the pluralistic governance;

- organise periodic meetings to gather the needs and expectations of the local actors and arrange discussions dedicated to the preparedness of emergency response and recovery with national decision-makers and institutional organisations.

\subsection{Human health and safety issues}

The national stakeholder panels insisted on the strong concern of local populations about the potential health consequences of living in the affected territories, especially for children. They emphasized the large uncertainties regarding the possible long-term effects of low doses exposure. 
Indeed, the presence of radioactivity in the environment creates strong disturbances in the daily life of locals, inducing social and psychological concerns (Kuroda et al., 2018; Lochard et al., 2019):

- health consequences could occur several years and decades following the exposures (i.e.: thyroid cancers cardiovascular and cognitive diseases, etc.). The anticipation of these possible consequences and the answer to locals' fears raised concerns such as how to lower the stress level?, How to implement an appropriate health follow-up without causing unnecessary fears?;

- a significant modification of the demography of local communities may be observed, requiring an evolution or at least an adaptation of the healthcare infrastructure (e.g.: predominance of elderly people in some communities, presence of workers involved in the dismantling of the damaged nuclear installation, etc.);

- the long-term follow up of health consequences of exposures to low doses is also difficult to address for both local populations and health professionals. Furthermore, the consequences of the accident on the well-being of the population requires more effort be put on the social and psychological support to allow them to recover their autonomy in resume their daily life.

Preparing in advance for the key issues to be addressed in the health surveillance strategy, and identifying the available and needed resources for its implementation would contribute to improve the management of health issues if an accident occurs. For this purpose, it would be useful to prepare the framework for implementing health surveillance strategy in case of an accident. This requires actions to:

- establish a dialogue with health professionals and local stakeholders to identify the key issues at stake in case of an accident;

- identify the overall objective of the health surveillance strategy for post-accident situations and share it with health professionals and local stakeholders around nuclear installations;

- identify the available resources at the local and regional levels for the implementation of this strategy and define the needs for their adaptation in case of an accident;

- identify the role and responsibilities of the different stakeholders (including local, regional and national health agencies and professionals, NGOs, local populations...);

- favour the development of the radiological protection culture for the different stakeholders.

\subsection{Environmental issues}

The management of the environmental consequences of a nuclear accident can involve various uncertainties, either concerning the radiological characterisation itself (e.g. measurement and analysis capabilities available at the time of the accident), or the remediation strategies implemented, their effectiveness and the possible impacts of these strategies (e.g. waste production and related storages, etc.). The national panels identified uncertainties related to environmental issues such as the variation of agricultural and animal productions throughout the year (e.g. flowering or harvest periods, indoor/ outdoor times for animal productions, etc.), implying totally different consequences depending on the season of an accident. For this reason, to be most effective, countermeasures have to be adapted to the real state of the production (Nisbet et al., 2010). They also stressed that sometimes, the theoretical calendar of agricultural production can differ from the real state of production (due to meteorological conditions for instance). To better cope with such uncertainties, realistic characterisations of the affected zones and the states of their agricultural and animal production at the time of the accident are needed. In the preparedness phase, it seems necessary to better consider the seasonality and characteristics of agricultural and animal productions. This would imply actions to:

- study in depth the characteristics of agricultural areas to select and model countermeasures (identify sensitive and less sensitive areas, etc.);

- create a knowledge database of land uses, agricultural and husbandry productions and feedstuff calendars;

- on this basis, establish a metafile with the countermeasures adapted to the type of soil and crops and protective actions associated with animal productions;

- develop a process in order to be able to quickly acquire the real development state of agricultural productions during the crisis management.

Feedback from Chernobyl and Fukushima accidents also emphasizes that uncertainties related to the radiological characterisation of environment itself can arise. It is indeed difficult to obtain a clear view of the impact of radioactive releases shortly after the accident and this can sometimes lead to uncertainties on the relevance of the implemented protective measures in comparison with the real state of the environment (Nisbet et al., 2010). All the national panels acknowledged the fact that measurements can clearly help to improve and refine the first global environmental characterisation provided by models. However, panels raised uncertainties on the ability to deploy measurement campaigns rapidly as well as to perform large amount of analysis: "Will the technical resources be available?", "How to deal with a great demand for sample analysis?", etc. In this context, it transpires that monitoring measurements are the ultimate proof of the reality of the contamination and it is necessary, in the preparedness phase, to develop or maintain a comprehensive and effective monitoring capability to be able to provide such information at the time of the accident. Concrete actions could be to:

- arrange a national capacities register, harmonize procedures and maintain homologated control of quality of the measurement requirements;

- implement direct measurement equipment, to make rapid screening of contaminated zones;

- establish a monitoring process for the effective radiological characterisation of large geographical areas.

The national panels also identified uncertainties regarding the impact of decontamination on waste production and management. In particular, they stressed uncertainties associated with the types of generated waste, the associated amounts, the potential availability of storage facilities and the existing criteria for managing this situation: "What types of waste will be produced?" "On what criteria will they be categorized?" "How to assess in advance the amount of waste?". The 
Fukushima experience, where the decontamination strategies generated a considerable amount of waste (nearly 17 million cubic metres), mostly accumulated in villages within temporary storage facilities, shows that inhabitants are concerned about the large amount of waste and its impact on their territory. Facing these uncertainties, it seems important to anticipate the waste consequences linked to the protective decisions and prepare the means for an appropriate management. This implies actions to:

- implement or continue studies linking protection strategies and waste production;

- put in perspective costs/benefits of waste generation with radiological protection.

\subsection{Social aspects}

Many social aspects causing significant uncertainties in the decision-making were pointed out in the panels. They mainly deal with acceptance, trust and compliance related to protective actions, information and communication with the public, and social consequences of the implemented countermeasures. Most of the panels highlighted the difficulties associated with the uncertain compliance of the population and local stakeholders with the proposed protective actions in the sense that they may not necessarily comply with instructions given by the authorities. As previously noted by authors such as Burns and Slovic (2012) or Eiser et al. (2012), disasters are not only determined by their magnitude or unpredictability, but also by how people respond to them. On that perspective, different aspects were emphasized: "Will public understand the recovery actions?" "How the population will react to governmental control (countermeasures implemented, waste storage issues, etc.)?", "Will different regions react differently?". A second social aspect was related to public communication of the proposed measures and about food safety, in relation with consumers trust. The panels pointed out the difficulty to communicate clear and audible messages to the population, which has been previously pointed out in the literature (Perko, 2011). Different aspects were identified, such as: "How to better communicate about countermeasures in order to ensure understanding and compliance?", "How to better inform public and consumers on the radioactivity concentrations in food?", "What are the effective communication channels that consumers/public will trust in - farmers, producers, retailers?". A third group of social aspects was related to potential consequences or impacts of some protective actions in the population: "Where and how the population will be relocated?", "how to outreach to the general population and the hosting territories so as not to generate stigmatization of the relocated individuals and affected territories?". Therefore, during the emergency and transition phase, the decision-making process is associated with many social uncertainties that should be considered and prepared in advance. For this purpose, two recommendations have been suggested: to gather information on post-disaster behaviour of population and adapt, if necessary, the emergency response strategies and to investigate innovative strategies of communication on uncertainties related to the implementation of protective actions.

The gathering of information may consist in:

- performing in-depth analysis of the behaviour of populations affected by previous NPP accidents and other technological catastrophes;
- carrying out psychosocial studies on the behaviour of the population in case of potential nuclear emergency using scenarios and other stimuli, adapted to the national and cultural contexts;

- adapting subsequently the EP\&R plans.

For the innovative strategies of communication on uncertainties, the concrete actions are to:

- initiate brainstorming between experts, decision-makers and local stakeholders to agree on the information needed to allow the population to better understand the complexity of the situation as well as the related decisions taken by the authorities and to better adapt their behaviours;

- continue testing new communication tools (e.g. SMS, flexible messages) and strategies better reflecting uncertainties (e.g. content, timing of communication, relevant communicators, etc.);

- to limit rumours, fake news or confusion related to "uncertainties" and to avoid panic reactions, developing in advance education and training and equipping communicators is useful;

- test innovative strategies of communication during mediatraining, practical case studies and exercises involving experts, decision-makers, and if possible journalists and the population.

\subsection{Economic aspects}

A nuclear accident creates strong and long-lasting disturbances on the socio-economic situation at the local, national and even international levels. In an inevitable context of loss of image for local productions, interactions between the various economic actors are upset with a high risk of loss of mutual trust and confidence between producers, distributors and consumers (Schneider et al., 2019).

One of the main uncertainties raised by national panels is the lack of knowledge and feedback about the direct and indirect costs of implementing protective measures. These costs come from the control of countermeasures' efficiency as well as with actions taken for rehabilitate the image of the local products. Farmers and producers wonder whether their activity will be maintained in case of temporary evacuation and relocation: "Who will pay for the human resources and technical equipment required?", "What will be the indirect costs of the protective actions to implement?". In addition, the producers and distributors wonder whether consumers will continue to buy the presumably affected products (i.e. those produced in the presumably affected area) and what could be the possible impacts on their selling prices: "What about the brand damage/loss for the products?", "How will the different sectors of production of food and other goods be impacted, especially if they have been stigmatized in media, or social media?". More broadly, the anticipation of economic consequences on domestic and export markets was identified as a crucial uncertainty, in particular, emblematic products ( $e$. $g$. wine) or important sectors for the local or national economy (e.g. tourism). To address these uncertainties, the economic impact of protection strategies has to be taken into account in the decision-making process and thus, it is necessary during the preparedness phase to further develop decision support 
tools integrating potential economic impacts of protection strategies. It is recommended to:

- prepare feedback analyses on the economic impacts of the protection strategies implemented following the Chernobyl and Fukushima and other technological accidents;

- estimate costs associated with the implementation of protective actions following an accident in accordance with the local and national frameworks;

- further develop models to calculate and anticipate direct and indirect costs and further elaborate risk/benefit analysis for various sets of rehabilitation scenarios.

The national panels also highlighted uncertainties related to existing financial supports mechanisms which could be implemented following a nuclear accident, both for compensating economic damages and losses and accelerating the resumption of activities. In particular, panels questioned if the existing financial supports would be substantial enough and made rapidly available to avoid financial gaps and to rapidly resume economic activities. To be prepared in case of an accident, it is necessary to review existing financial supports and mechanisms that could be implemented rapidly to resume economic activities as of the transition phase. This implies concrete actions to:

- review financial mechanisms implemented after natural or technological disasters;

- identify which organizations are (could be) involved in providing financial support at the national and international levels;

- investigate the financial resources and compensation mechanisms that could be rapidly available and the related amounts that could be allocated for different types of nuclear accidents (considering immediate economic losses and costs for implementing countermeasures).

The national panels also have revealed that many socioeconomic actors are unaware of the possible financial supports that could be provided and by whom. Therefore, these actors would face uncertainties when taking decisions related to the resumption of their activity. To cope with these uncertainties, it is necessary to consider in advance the needs of socioeconomic actors by making more efficient and accessible financial supports and mechanisms in order to promote an early resumption of economic activities. This recommendation leads to actions to:

- develop practical case studies illustrating different options for the resumption of economic activities following a nuclear accident;

- discuss and challenge these case studies with relevant stakeholders;

- develop specific infrastructures - e.g. around nuclear installations - to improve the dialogue, coordination and information of socio-economic and political actors (including NGOs and citizen) and to help them to take informed decisions in case of an accident.

\subsection{Transversal issues}

The production, the use and the support of information raise a large number of uncertainties, both during the emergency and transition phases. The panels clearly emphasised the importance of providing decision-makers with information, not only focusing on radiological aspects. Indeed, they insisted on the importance of obtaining information on radiological contamination in order to take informed decisions, together with complementary information. For instance, they expressed their interest on: "What is the sociological profile of the population?", "What is the level of self-sufficiency of the population (consumption of the food produced in garden, harvest in forest, hunting, etc.)?", "What are the agricultural characteristics of the affected sectors?". Therefore, detailed information about the various issues at stake in the affected territory (e.g. types of farms and food production, location of public establishments, etc.) can be a real asset to support decision-makers, who can adapt their decisions according to the socio-economical context. In addition, feedback from post-accident situations shows that it is also crucial to provide detailed information about the behaviour of population at the time of the accident. Therefore, additional information such as geographical, environmental, socio-economic data of the local territory needs to be collected in advance. Decisionmakers also need up-to-date local data during the crisis management to adapt their decisions and strategies. To improve the decision-making process, it is crucial to foster the production and the provision of comprehensive and up-todate information for the decision-making process to include other aspects than radiological issues. In the preparedness phase, this recommendation would imply actions such as:

- to establish/reinforce "reference" status of the territory: reference levels (background levels maps), cancer registry, local data (population ages, location of public-access buildings, etc.), endangered species, protected areas, socioeconomic issues, population food dietary, etc.;

- to set up a metafile aggregating all the data of the territory: create databases that are not yet available (cancer registry, epidemiological data, agricultural productions database, etc.);

- to develop dedicated tool for automatic update of databases;

- to prepare, with the stakeholder network survey, questionnaires to be given to the affected population following the accident, to adapt health, social and financial supports;

- to identify actors to be involved for specific issues following the accident (e.g. qualified companies for decontamination).

During the emergency and transitions phases, it would be recommended to:

- ensure the periodic integration of local situation inputs into assessments, and provide periodical up-to-date data on:

- agricultural production (livestock, harvesting crops/ imminent date on the market),

- accurate level of home-consumption of people (including those living in precarious conditions),

- socio-economic activities (e.g. non-interruptible activities, tourism, etc.);

- get information on seasonal activities (e.g. social events, tourism, etc.).

Moreover, all participants highlighted the need to reflect uncertainties in supporting information, as clearly as possible. The frequency maps, developed in the framework of 
CONFIDENCE WP1 (Korsakissok et al., 2017, 2020) seek to reflect the various uncertainties associated with the modelling process by delimiting different areas of probability of occurrence of threshold exceedance according to the selected criteria. These maps were designed to be used in the early release phase, when measurement data are not yet available. However, these maps have raised some difficulties to the panels, such as not clearly reflecting uncertainties associated with the boundaries of the delimited zones. After a nuclear accident and as soon as possible, the decisions would be based on maps from measurements. The reliability of the measurements made to establish the specific zones concerned by the protective action was also largely questioned: "How to ensure that the boundaries of the zoning for relocation actually protect the individuals living nearby?". Overall, the panel's discussions concluded that probability maps are good support of information, reflecting very well uncertainties related to modelling and measurement processes and so helping decision-makers to take informed decision. In addition, it transpires that other maps providing environmental, social and economic issues at stake in affected territories also help decision-makers to better catch the strengths and vulnerabilities of the impacted territory (Charnock et al., 2020). To better guide decision-makers, it is necessary to improve the support of information reflecting uncertainties inherent in the situation to better guide decision-makers. Practical actions lead to:

- work on support of information that reflect uncertainties clearly (e.g. probability maps). More particularly, ensure to:

- reflect uncertainties related to the boundaries of the zoning,

- compare data resulting from modelling and from measurements,

- anticipate the spatial and temporal evolution,

- identify with stakeholders the more relevant representations of uncertainties;

- create a geographical information system integrating useful data for the decision-making process.

\section{Conclusion and perspectives}

This paper highlights 14 recommendations aimed to improve decision-making processes after a nuclear accident, most notably by encouraging the implementation of practical actions in the preparation phase. These recommendations were elaborated by considering the views and concerns of stakeholders from nine national panels. Based on the pre-defined categories of uncertainties, the main outcomes of national panels have been highlighted, and then compared and combined to draw up general recommendations with a European scope. These recommendations have also been challenged with experts and end-users during the CONFIDENCE Dissemination Workshop in Bratislava (Duranova et al., 2020). Among the different topics addressed, it should be noted that stakeholders highlighted the importance of holistic approaches, and the feedback experience from past nuclear incidents, but also from other types of accidents. This research represents the first attempt to structure and derive general recommendations to face uncertainties in the decision-making processes during emergency and transition phases. It requires further research, and more importantly, actions to implement these recommendations in a practical way, within each territory that could potentially be affected by a nuclear accident. For this purpose, it would be useful to discuss these recommendations at different levels:

- at international and European levels (e.g. OECD, European platforms) notably to address the economic impacts of past nuclear accidents, social behaviours following disasters, etc.;

- at the research community levels, to further explore some research activities pointed out by the panels (e.g. need to develop tools to better guide decision-makers such as visualizations of uncertainties, calculation of economic or environmental impacts, "option thinking" tools, etc.);

- at national level with public authorities to further explore the governance associated with the decision-making processes. For instance, the issues related to the roles and responsibilities of the actors involved in the decisionmaking process can be discussed, as well as the setting up of sustainable network of stakeholders to be involved in the preparedness;

- at the local level to discuss on the implementation of these recommendations and ensure that they will be adapted to their needs and local specificities. It would be useful to maintain the stakeholders' networks established with the panels and to further discuss these recommendations, and improve them or to apply them, during the national nuclear exercises.

Therefore, the implementation of these recommendations is the new challenge ahead.

Acknowledgement. The work described in this paper was conducted within the CONFIDENCE project which was part of the CONCERT project. This project has received funding from the Euratom research and training programme 2014 2018 under grant agreement No 662287.

Disclaimer (Art. 29.5 GA). This publication reflects only the author's view. Responsibility for the information and views expressed therein lies entirely with the authors. The European Commission is not responsible for any use that may be made of the information it contains.

\section{References}

Averin V. 2016. Belarus' experience in post-Chernobyl communication with the local population, and some lessons learnt from involvement in the NERIS-TP project. Radioprotection 51(HS1): S43-S45.

Ban N. 2016. Japanese experience in stakeholder involvement: ICRP Dialogue meetings. Radioprotection 51(HS1): S51-S53.

Baudé S, Hériard-Dubreuil G, Schneider T. 2016. Local populations facing long-term consequences of nuclear accidents: Lessons learnt from Chernobyl and Fukushima. Radioprotection 51(HS2): S155-S158.

Burns WJ, Slovic P. 2012. Risk perception and behaviors: Anticipating and responding to crises. Risk Anal. 32(4): 579-582.

Charnock T, Andersson K, Trueba C, Montero M. 2020. Uncertainties confronting stakeholders and decision-makers in planning 
intervention in urban and agricultural scenarios in the transition phase of a radiological emergency. Radioprotection 55(HS1). https://doi.org/10.1051/radiopro/2020021.

Charron S, Lafage S, Van Asselt E, Baptista M, Van Bourgondien M, Brandhoff P, Cabianca T, Camps J, Cessac B, Crouail P, Durand V, Gallego E, Gil O, Holmes S, Hourdakis C, Jones K, Kamenopoulou V, Lecomte JF, Liland A, Lopes I, Madruga MJ, Martins JO, Mc Mahon C, Montero M, Murith C, Olyslaegers G, Organo C, Paiva I, Peltonen T, Portugal L, Potiriadis C, Prades A, Reis M, Rossignol N, Schneider T, Sala R, Smith V, Tafili V, Teles P, Tomkiv Y, Trueba C, Turcanu C, Turtiainen T, Twenhöfel C, Vaz P. 2016. Overview of the PREPARE WP3: Management of contaminated goods in postaccidental situation-Synthesis of European stakeholders' panels. Radioprotection 51(HS2): S83-S91.

Duranova T, Raskob W, Beresford NA, Korsakissok I, Montero M, Müller T, Turcanu C, Woda C. 2020. CONFIDENCE dissemination meeting: Summary on the scenario based workshop. Radioprotection 55(HS1). https://doi.org/10.1051/radiopro/ 2020009.

Eiser JR, Bostrom A, Burton I, Johnston DM, McClure J, Paton D, Joop Van der Pligt J, White MP. 2012. Risk interpretation and action: A conceptual framework for responses to natural hazards. Int. J. Disaster Risk Reduct. 1: 5-16.

Gallego E, Montero M. 2016. Experience in Spain with local-national fora for better post-accident preparedness. Radioprotection 51 (HS1): S31-S34.

Korsakissok I, Périllat R, Didier D, Bedwell P, Leadbetter S, Szanto P. 2017. Published sets of probability maps of threshold exceedance for scenarios provided to WP4, WP5 \& WP6. CONCERT Deliverable 9.3. Available from https://concert-h2020.eu/en/ Publications.

Korsakissok I, Périllat R, Andronopoulos S, Bedwell P, Berge E, Charnock T, Geertsema G, Gering F, Hamburger T, Klein H, Leadbetter S, Lind OC, Pazmandi T, Rudas C, Salbu B, Sogachev A, Syed N, Tomas J, Ulimoen M, De Vries H, Wellings J. 2020.
Uncertainty propagation in atmospheric dispersion models for radiological emergencies in the pre- and early release phase: Summary of case studies. Radioprotection 55(HS1). https://doi. org/10.1051/radiopro/2020013.

Kuroda Y, Iwasa H, Orui M, Moriyama N, Nakayama C, Yasumura S. 2018. Association between health literacy and radiation anxiety among residents after a nuclear accident: Comparison between evacuated and non-evacuated areas. Int. J. Environ. Res. Public Health 15(7): 1463.

Lochard J, Schneider T, Ando R, Niwa O, Clement C, Lecomte JF, Tada JI. 2019. An overview of the dialogue meetings initiated by ICRP in Japan after the Fukushima accident. Radioprotection 54 (2): $87-101$.

Montero M, Sala R, Maitre M, Durand V, Nunes-Marques P, Reis M, Crouaïl P, Trueba C, Paiva I, Gil OM, Schneider T. 2020. Guidelines and recommendations for decision making during the transition phase. CONCERT Deliverable 9.24. Available from https://concert-h2020.eu/en/Publications.

Nisbet AF, Andersson KG, Duranova T. 2010. Demonstration of generic handbooks for assisting in the management of contaminated food production systems and inhabited areas in Europe. Radioprotection 45(5): 243-249.

Perko T. 2011. Importance of risk communication during and after a nuclear accident. Integr. Environ. Assess. Manag. 7(3): 388-392.

Raskob W, Schneider T, Gering F, Charron S, Zheleznyak M, Andronopoulos S, Heriard-Dubreuil G, Camps J. 2016. Innovative integrative tools and platforms: Key results of the PREPARE European Project. Radioprotection 51(HS2): S59-S61.

Schneider T, Maître M, Lochard J, Charron S, Lecomte J-F, Ando R, Kanai Y, Kurihara M, Kuroda Y, Miyazaki M, Naito W, Orita M, Takamura N, Tanigawa K, Tsubokura M, Yasutaka T. 2019. The role of radiological protection experts in stakeholder involvement in the recovery phase of past-nuclear accident situations: Some lessons from the Fukushima-Daiichi NPP accident. Radioprotection 54(HS4): 259-270.

Cite this article as: Durand V, Maître M, Crouaïl P, Schneider T, Sala R, Marques-Nunes P, Paiva I, Monteiro Gil O, Reis M, Hilliard C, Tafili V, Twenhöfel C, Van Asselt E, Trueba C, Montero M, Duranova T. 2020. Towards an improved decision-making process to better cope with uncertainties following a nuclear accident. Radioprotection 55(HS1): S135-S143 